\title{
A comparative study on the role of antenatal care services and child care at various rural and tribal villages, Adilabad, Telangana state.
}

\section{G.Sreekanth ${ }^{1}$, Kusuma Nirmala ${ }^{2}$, A.Ravinder ${ }^{3}$}

1. Associate professor, Department of Community Medicine , Rajiv Gandhi Institute of Medical Sciences ,Adilabad, Telangana state

2. Medical Officer, Civil Assistant Surgeon, Primary Health Centre, Ellandhakunta, Karimanagar, Telangana.

3. Tutor cum Lecturer, Statistician , Department of Community Medicine, Rajiv Gandhi Institute of Medical Sciences ,Adilabad , Telangana state DOI : 10.47799/pimr.0802.19

Background: Reproductive, maternal, newborn and child health is one of the four categories of the universal health coverage indicators under sustainable development goals target 3.9: family planning, antenatal care (minimum 4 visits), with skilled attendants at birth, full child immunization coverage, and health seeking behavior for suspected child pneumonia ${ }^{1}$. Achievement under millennium development goals shows that in developing countries like India, mostly in tribal villages continue to face the greatest challenges in improving the maternal and child health struggling with a combination of poor coverage and quality of health care services and public health interventions. The hard to reach tribal areas face obstacles in ensuring universal access to sexual, reproductive health services ${ }^{2}$. The indicators showed lower performance among the tribal communities as seen with most of the health indicators. Poverty, low literacy and poor nutritional status of reproductive age women give rise to poor maternal and child health outcomes along with lack of healthcare delivery facilities lead poor maternal health indicators ${ }^{3}$.

Methods: A comparative study was conducted on 243 randomly selected mothers who have children less than 7years in rural and tribal villages (150 and 93 respectively). This is community based cross-sectional study and done by using a pre-tested structured questionnaire for data collection at Shanthapur, a rural village and various tribal villages, at an average $25 \mathrm{kms}$ away from Adilabad town from Jan-October 2019. Analysis was done using SPSS for windows version 16 , Microsoft excel and Open epi website.

Result: Out of 243 study subjects, 85\% (206) of the study subjects were registered for the antenatal services. The mean age of mother at pregnancy, female literacy, birth order, number of antenatal visits, person conducting delivery, place of delivery, birth weight of child, number of breastfeeding per day, exclusive breastfeeding, total stoppage of breastfeeding ,baby hospitalization due to sickness, weight per age and height per age of the child are statistically significant $(p<0.05)$ between the rural and tribal study subjects.

Conclusion and Recommendation: This study revealed that utilization of ANC services and child care services are far better by rural women than the tribal women. The role of antenatal care and child care being influenced by difficulties of accessibility, availability of these services at tribal areas are exposed from this study.

Keywords: antenatal care, child care, health service utilization, tribal, rural, nutritional indicators

\section{Introduction}

Antenatal care services were considered to be key element in the primary health care delivery system of a country which aims for a healthy society. Utilization of Antenatal Care (ANC) services and maternal and child health programs were critically important in a country like India which is experiencing high infant and child mortality rate and maternal mortality rate. As per NFHS-4, Under-5 mortality rate declined in India from 74 in 2005-06 to 54 in 2015-16. Under-5 mortality rate in India was 54 in 2015-16 and in rural, tribal areas, Infant mortality rate was 43, 60 in 2015-16 simultaneously 4 . Over the past sixty years maternal health situation in the country has been staggering despite several changes in a rapidly evolving socioeconomic environment. In the last decade, as per the national data, health indicators including utilization of antenatal care services were as poor as $30 \%$ in tribal India ${ }^{5}$. Tribal people are the people who are underserved due to problems of geographical and those who suffer social and economical disadvantages such as Scheduled caste or Scheduled tribes and the urban poor ${ }^{6}$

There is an excellent pyramid of infrastructure for the delivery of maternal and child health services through a network of sub centers and PHC centers in rural India. But still, most child deliveries are conducted at home by traditional birth attendants and relatives. The Child Survival and Safe Motherhood, now a component of Reproductive and Child Health Program, is initiated to achieve a substantial improvement in the health status of women and children in India. It includes early registration of pregnancy, at least three antenatal check-ups, universal coverage with tetanus toxoid and iron and folic acid tablets, early detection and referral of at risk mothers, deliveries by trained health personnel, facilities to manage obstetrical medical emergencies and birth spacing ${ }^{7}$ 
Maternal age at pregnancy is very important to be considered because age below 20 years and above $30-35$ years increases the chances of maternal mortality. Women education has been neglected since ages with priority for household chores in India. Literacy rates are much lower in tribal communities than in rural. Parity of women below 2 is important to have a good health of the mother. The number of children born to tribal women is far more to the rural women. Birth spacing is the time interval between the births. A minimum of 3 years as to be maintained between the pregnancies ${ }^{8}$.

Ideally every women as to get registered of their pregnancy with health facility as early as possible within 12 weeks of pregnancy. Minimum of 4 antenatal checkup are required by the pregnant women at least before she delivers the baby. a trained female health assistant is qualified to conduct health checkups of normal antenatal and postnatal cases. A trained / skilled birth attendance like dai is qualified to provide delivery assistance to normal uncomplicated cases. Pregnant mothers suffering from associated systemic diseases are referred to appropriate centers for doctor management. To encourage institutional deliveries the Government of India is training dai to reduce home deliveries ${ }^{6}$.

Prelacteal feeds are those foods given to newborns before breastfeeding is established or before breast milk "comes in," usually on the first day of life. Prelacteals include honey, jaggery (brown sugar from sugar cane) ghee (clarified butter), and ghutti(herbal paste). According to World health organization a newborn with weight of 3500 to 2500 grams within first hour of birth is called normal birth weight. Breastfeeding is an important child survival intervention. Breastfeeding within an hour of birth could prevent $20 \%$ of newborn deaths. Infants who are not breastfeed are 15 times more likely to die from pneumonia and 11 times more likely to die from diarrhea than children who are exclusively breastfed which are the two leading causes of death among under five. Newborn babies are exclusively breastfed during the first six months and the babies between 6 months and 8 months are given complementary foods. Complementary feeding or weaning is the process of withdrawal of the child from the breast milk to external force it should be done gradually so that the child gets adjusted to external force which will be started from 6 th month onwards because the mother's milk will not be sufficient for the growth and development of the child. Diamond feeding of the best milk product child will be done no restrictions on the frequency and duration of breastfeeding child is fed till it is contended and satisfied. That means the baby should be allowed to breastfeed and restrictedly. It is the child who should decide the frequency and duration of feeding and not the mother. Growth monitoring of the child will be done by recording of the height periodically against the age and weight against the standard height that is height for age weight for height and the height finished the mid arm circumference the weight for age and height for age are agedependent that is age of the child should be known ${ }^{6}$. I had chosen the study to assess the differences of antenatal and child care services between the rural and tribal women.

Aim: To compare the antenatal and child care services utilization in rural and tribal women.

\section{Objectives:}

1. To demographic profile of the study which as a role in utilization of antenatal services

2. To compare the antenatal care services utilization in rural and tribal women study subjects.

3. To compare the child care and nutritional indicators of rural and tribal women study subjects

\section{Methods:}

A community-based cross sectional study was conducted on mothers who have children less than 7years by using a pretested structured questionnaire for data collection at Shanthapur, a rural village, and Arjuni, Kolamguda, Lohara , Jamini, Mamidiguda, Nandigama, Kandala, Pothaguda , Dahiguda, Gunjala ,Linguguda, Tekdiguda, Chinna maleboregav, Pendurluddi were tribal villages, at an average $25 \mathrm{kms}$ away from Adilabad town from Jan -October 2019 . The study was conducted on 243 (150 from rural and 93 from tribal) randomly selected women on convenience, house to house visit and taken consent. Analysis was done using SPSS for windows version 16, Microsoft excel and Open epi website. Inclusion criteria: Mothers who have children less than 7years and Mothers who have undergone the recent pregnancy

Exclusion criteria: Mothers who doesn't give consent were excluded

Results:

Picture: 1 Pie chart shows the number and percentage of mothers according to their locality.

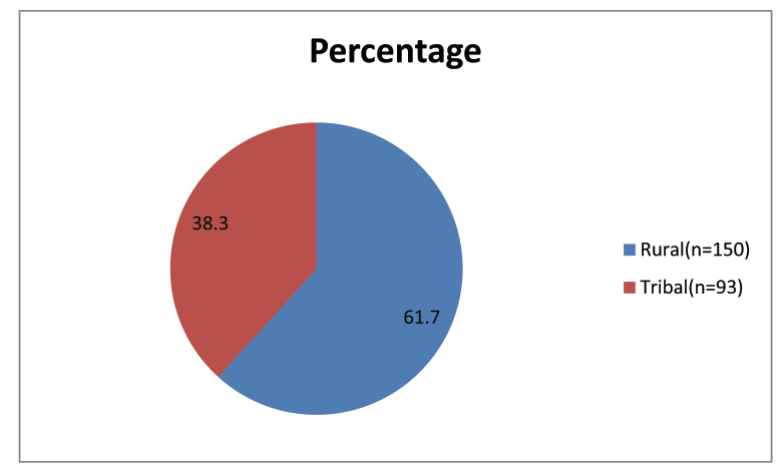

The study subjects selected for the study were mothers of less than $7 y$ rs old children from rural and tribal villages. 
Table: 1 shows the comparison of maternal age, female literacy and birth spacing in rural and tribal subjects.

\begin{tabular}{|c|c|c|c|c|c|}
\hline & $\operatorname{Rural}(\mathrm{n}=150)$ & Percentage & Tribal(n=93) & Percentage & $p$ value \\
\hline Maternal age at pregnancy & $22.612+-3.528$ & & $22.129+-5.597$ & & $0.000001^{*}$ \\
\hline \multicolumn{5}{|l|}{ Female literacy } & \multirow{4}{*}{$0.0000001^{*}$} \\
\hline$>$ Secondary & 118 & 78.7 & 12 & 12.9 & \\
\hline Primary & 13 & 8.7 & 28 & 30.1 & \\
\hline Illiterate & 19 & 12.7 & 53 & 57.0 & \\
\hline \multicolumn{5}{|l|}{ Birth spacing } & \multirow{4}{*}{0.121} \\
\hline Primi & 69 & 46 & 32 & 34.4 & \\
\hline $12-24 m$ & 45 & 30 & 39 & 41.9 & \\
\hline$>24 m$ & 36 & 24 & 22 & 23.7 & \\
\hline
\end{tabular}

The maternal mean age at pregnancy of the rural women are higher than the tribal women and the difference was statistically significant $(p<0.000001)$. Literacy level is higher in more number of rural women than the tribal women and the difference is statistically significant $(p=0.00000001)$. No statistical difference for birth spacing of pregnancies.

Table: $\mathbf{2}$ shows the comparison of registration of pregnancy, birth order, number of antenatal visits, person conducting delivery and place of delivery in rural to tribal women.

\begin{tabular}{|c|c|c|c|c|c|}
\hline & Rural(n=150) & Percentage & Tribal( $(n=93)$ & Percentage & $p$ value \\
\hline \multicolumn{5}{|c|}{ Registration of pregnancy } & \multirow{3}{*}{0.07927} \\
\hline Yes & 131 & 87.3 & 75 & 80.6 & \\
\hline No & 19 & 12.7 & 18 & 19.4 & \\
\hline \multicolumn{5}{|l|}{ Birth order } & \multirow{4}{*}{$0.00002596 *$} \\
\hline 1 & 79 & 52.7 & 32 & 34.4 & \\
\hline 2 & 56 & 37.3 & 30 & 32.3 & \\
\hline$>=3$ & 15 & 10.0 & 31 & 33.3 & \\
\hline \multicolumn{5}{|c|}{ Number of antenatal visits } & \multirow{3}{*}{$<0.0000001^{*}$} \\
\hline less than 4 & 38 & 25.3 & 75 & 80.6 & \\
\hline above 4 & 112 & 74.7 & 18 & 19.4 & \\
\hline \multicolumn{5}{|c|}{ Person conducted delivery } & \multirow{3}{*}{$<0.0000001^{*}$} \\
\hline Skilled birth attendant & 10 & 6.7 & 39 & 0.4 & \\
\hline Doctor & 103 & 68.7 & 38 & 40.9 & \\
\hline ANM & 37 & 24.7 & 16 & 17.2 & \\
\hline
\end{tabular}




\begin{tabular}{|l|c|c|c|c|c|}
\hline Place of delivery & & & & \\
\hline Hospital & 140 & 93.3 & 68 & 73.1 & $0.00001^{*}$ \\
\hline Home & 10 & 6.7 & 25 & 26.9 & \\
\hline
\end{tabular}

$84.8 \%$ (206) of the study subjects were got registered with antenatal services and $19.3 \%$ (18) of the tribal women had not registered their pregnancy. More the tribal women has birth order more than 2 than the rural women and the difference is statistically significant $(p=0.000025)$. Tribal women has low antenatal visits $(<4)$ to rural women and the difference is statistically significant $(p<0.000001)$. More number of tribal women has underwent the delivery by Skilled birth attendant at home compared to rural women and the difference is statistically significant $(p<0.000001)$.

Table: 3 shows the comparison of birth weight of the child, number of breast feedings per day, duration of exclusive breast feeding, time of stoppage of breast feeding in rural and tribal women.

\begin{tabular}{|c|c|c|c|c|c|}
\hline & Rural( $(n=150)$ & Percentage & Tribal( $(n=93)$ & Percentage & $p$ value \\
\hline Birth weight & $2.844+-0.513$ & & $2.7+-0.44$ & & $p=0.025^{*}$ \\
\hline \multicolumn{5}{|l|}{ Pre-lacteal feeds } & \multirow{3}{*}{0.16} \\
\hline Yes & 20 & 13.3 & 7 & 7.5 & \\
\hline No & 130 & 86.7 & 86 & 92.5 & \\
\hline \multicolumn{5}{|c|}{ Number of breast feeding per day } & \multirow{4}{*}{$0.0003773 *$} \\
\hline$<8$ & 33 & 22 & 13 & 14.0 & \\
\hline 8 to 12 & 84 & 56 & 37 & 39.8 & \\
\hline$>12$ & 33 & 22 & 43 & 46.2 & \\
\hline \multicolumn{5}{|c|}{ Exclusive breastfeeding } & \multirow{3}{*}{$0.0000001^{*}$} \\
\hline less than 6 months & 37 & 24.7 & 53 & 57.0 & \\
\hline above 6 months & 113 & 75.3 & 40 & 43.0 & \\
\hline \multicolumn{5}{|c|}{$\begin{array}{l}\text { children 6-8months receiving } \\
\text { solid/ semisolid food and } \\
\text { breastmilk }\end{array}$} & \multirow{3}{*}{$0.0195 *$} \\
\hline No & 5 & 3.3 & 10 & 10.8 & \\
\hline Yes & 145 & 96.7 & 83 & 89.2 & \\
\hline
\end{tabular}

Mean birth weight of tribal women children is lower than the mean birth weight of rural women children and the difference is statistically significant ( $p=0.025$ ). $56 \%$ of the rural study subjects $39.8 \%$ of tribal study subjects breast feed their children 8-12 times a day and the difference of number of breast feeding per day was higher for tribal women compared with rural women and the difference is statistically significant $(p<0.00037)$. Exclusive breastfeeding for more than 6 months was followed more by rural women than to tribal women and the difference is statistically significant $(p<0.000001)$. More number of rural women in the study continued breast feeding along with solid/semisolid food to their 6-8months old children compared to the tribal women subjects and the difference is statistically significant $(p=0.0195)$.

Table: 4 show the comparison of baby hospitalization for sickness, proportion of wasting and stunted children in rural and tribal study subjects. 


\begin{tabular}{|c|c|c|c|c|c|}
\hline & Rural(n=150) & Percentage & Tribal $(n=93)$ & Percentage & $p$ value \\
\hline \multicolumn{5}{|c|}{ Baby hospitalization } & \multirow{3}{*}{$0.00002^{*}$} \\
\hline Yes & 25 & 16.7 & 37 & 39.8 & \\
\hline No & 125 & 83.3 & 43 & 46.2 & \\
\hline \multicolumn{5}{|c|}{ Weight/age of child } & \multirow{3}{*}{$0.00001^{*}$} \\
\hline Wasting & 79 & 52.7 & 74 & 79.6 & \\
\hline Normal & 71 & 47.3 & 19 & 20.4 & \\
\hline \multicolumn{5}{|c|}{ Height/age of the child } & \multirow{3}{*}{$0.00001^{*}$} \\
\hline Stunting & 64 & 42.7 & 66 & 71.0 & \\
\hline Normal & 86 & 57.3 & 27 & 29.0 & \\
\hline
\end{tabular}

Baby hospitalization of tribal women due to diseases like acute respiratory illness, diarrhea, etc was more than the children of rural women and the difference is statistically significant $(p=0.00002)$. Wasting and stunting of the children was more in children of tribal women than in children of rural women and the difference is statistically significant $(p<00001)$.

\begin{tabular}{|c|c|c|c|c|c|c|}
\hline & \multicolumn{2}{|c|}{ My study } & \multicolumn{3}{|c|}{ India(NFHS-4) $[3,4]$} & \multirow{2}{*}{ Reason } \\
\hline Indicator & $\begin{array}{c}\text { Rural } \\
(\%)\end{array}$ & $\begin{array}{c}\text { Tribal } \\
(\%)\end{array}$ & $\begin{array}{c}\text { Rural } \\
(\%)\end{array}$ & $\begin{array}{c}\text { Tribal } \\
(\%)\end{array}$ & $\begin{array}{l}\text { National } \\
(\%)\end{array}$ & \\
\hline Registration of pregnancy & 87.3 & 80.60 & $90 \%$ & 83.80 & 85.3 & Matches \\
\hline $\begin{array}{l}\text { Delivery conducted by } \\
\text { skilled birth attendant }\end{array}$ & 6.6 & 41.9 & 4.9 & 71.5 & 81.4 & $\begin{array}{l}\text { More deliveries by } \\
\text { doctors and ANM }\end{array}$ \\
\hline $\begin{array}{l}\text { At least } 4 \text { antenatal } \\
\text { visits }\end{array}$ & 74.7 & 19.4 & 44.8 & NA & 51.2 & $\begin{array}{l}\text { tribal area minimum } \\
\text { accessibility }\end{array}$ \\
\hline Institutional delivery & 94 & 73.1 & 75.1 & 68 & 78.9 & Matches \\
\hline Exclusive breastfeeding & 75.33 & 43 & 56 & NA & 54.9 & tribal village \\
\hline $\begin{array}{l}\text { Children 6-8 months } \\
\text { receiving solid/semisolid } \\
\text { food and breast milk }\end{array}$ & 96.7 & 89.2 & 39.9 & NA & 42.7 & $\begin{array}{l}\text { women ignorant to } \\
\text { early start of weaning }\end{array}$ \\
\hline Wasting & 52.7 & 79.6 & 21.5 & 27.4 & 21 & \multirow{2}{*}{$\begin{array}{c}\text { more number of sickness } \\
\text { episodes in children }\end{array}$} \\
\hline Stunting & 42.7 & 71 & 41.2 & 43.8 & 38.4 & \\
\hline
\end{tabular}

\section{Discussion:}

The maternal mean age at pregnancy of the rural women is $22.612+-3.528$ and tribal women is $22.129+-5.597$ and the difference was statistically significant $(p<0.000001)$ and is compared to the mean age women at pregnancy to study by A.M.N.T. Adikari et $\mathrm{al}^{8}$ as $23.7+-3.74$. As per NFHS-4 ${ }^{4}$, literate rate of rural women was 61.7 which is lesser to the literacy level of rural women in the study is $87.4 \%$ than the tribal women and the difference is statistically significant ( $p=0.00000001$ ). mparison of maternal age, female literacy and birth spacing in rural and tribal subjects.

Conclusion and Recommendation: This study revealed that utilization of ANC services was relatively better for the rural study subjects than the tribal. This study proves that tribal 
communities perform less to worst because of illiteracy, poverty, malnutrition, difficult geographical terrains and isolation, lack of transportation, lack of health manpower , lack of concrete geographical plans and policies and above these all due to their beliefs in taboos, spiritual powers and faith healing, invalidated tribal remedies, compounded with lack of availability and accessibility to established systems of medicine are contributing to the failure of health care delivery to tribal population. Providing IEC and house-hold level discussion is important for ANC service utilization in the tribal women. Lots of research and policies have to be developed to improve the health care delivery improvisation in the tribal communities ${ }^{3}$.

\section{REFERENCES}

1. WHO (2015), health in 2015 from MDGs (millennium development goals ) to SDGs(sustainable development goals)

2. WHO(2016), world health statistics, 2016,Monitoring health for the SDGs

3. Manish Rana, Harsh Bakshi ,Anjali Modi , Priscilla Kayina ,Gneyaa Bhatt, Madhurjya Baruah IAPSM Textbook of Community Medivine, chapter:31 Urban Health ,Rural Health and Tribal health ,edition:1,2019, page:822-826

4. International institute for population sciences(IIPS) and ICF.2017. National Family Health Survey(NHFS-4). Mumbai:IIPS 2015-16

5. Roy MP, Mohan U, Singh SK, Singh VK, Srivastava AK. Determinants of utilization of antenatal care services in rural Lucknow, India. Journal of family medicine and primary care. 2013 Jan;2(1):55

6. AH Suryakanta, Textbook of community medicine and recent advances.5th edition 2019 , chapter 22, antenatal care, 503-551

7. Varma, Godi Rajendra; Kusuma, Yadlapalli Sriparvathi; Babu, Bontha Veerraju Antenatal care service utilization in tribal and rural areas in a South Indian district: an evaluation through mixed methods approach. The Journal Of The Egyptian Public Health Association: April 2011 , Volume 86 , Issue 1 and 2 , p 11-15, doi: 10.1097/ 01.EPX.0000395395.17777.be

8. A.M.N.T. Adikari* , R. Sivakanesan1, D.G.N.G. Wijesinghe2 and C. Liyanage3, Assessment of Nutritional Status of Pregnant Women in a Rural Area in Srilanka, Tropical Agricultural Research Vol. 27 (2): $203-211$ (2016)
How to cite this article : G.Sreekanth, Kusuma Nirmala A.Ravinder . A comparative study on the role of antenatal care services and child care at various rural and tribal villages, Adilabad, Telangana state. Perspectives in Medical Research 2020; 8 (2):88-93. DOI : 10.47799/pimr.0802.19

Sources of Support: Nil, Conflict of interest: None declared 